\title{
STRUCTURAL ANALYSIS OF STEERING YOKE OF AN AUTOMOBILE FOR WITHSTANDING TORSION/ SHEAR LOADS
}

\author{
S.K.Chandole ${ }^{1}$, M.D.Shende ${ }^{2}$, M.K.Bhavsar ${ }^{3}$ \\ ${ }^{1} P G$ Student, Mechanical Engineering, S.N.D. COE \& RC, Yeola, Nasik, Maharashtra, India \\ ${ }^{2}$ Associate Professor, Mechanical Engineering, S.N.D. COE \& RC, Yeola, Nasik, Maharashtra, India \\ ${ }^{3}$ Assistant Professor, Mechanical Engineering, Late G.N.S COE Anjneri, Nasik, Maharashtra, India
}

\begin{abstract}
The steering columns in a steering system are one of the main devices of an automobile. It is a very important part to attain stability and steady movement of the vehicle. It consists of two yokes, one on each shaft, connected by a cross-shaped intermediate member i.e. spider. Motion transmission system of vehicles consist several components which sometimes encounter unfortunate failures. Some common reasons for the failures may be manufacturing and design faults, maintenance faults, raw material faults, material processing faults as well as the user originated faults. In this paper finite element analysis of the component is carried out to find the stress and displacement of the final product. For modeling of the component, CATIA V5 R17 software is used. Preprocessing work like meshing and analysis work is carried out in HYPERWORKS software. Using FEA analysis, we can identify the nature and characteristics of stresses acting on the yoke and also evaluate the influence of the loads/mass/geometry/ boundary conditions over the yoke.
\end{abstract}

Keywords: Steering Yoke, Structural analysis, FEA, CATIA V5, Hyper works.

\section{INTRODUCTION}

The purpose of a steering system is to control the direction of the vehicle by operating the steering wheel of the steering system. Movement of steering wheel by the driver should cause an accurate response of the road wheels. The intermediate shaft connects the steering shaft to the steering pinion. These components cannot be arranged on the same axis due to the vehicle design limitations. They are arranged with the universal joints [1]. Control of vehicle should be maintained with safety throughout the speed range with little effort and over a wide range of road surfaces under all conditions [2-3].

The subassembly of steering yoke associated with this project work consists of two forged-steel yokes or forks joined to the two shafts being coupled and situated at right angles to each other. Although, the single component named 'Yoke' would be the topic of interest for this case-study. A spider hinges these two yokes together. Since the arms of the spider are at right angles [4]. The most common type of U-joint used in the automobile industry is Hooke or Cardan joint as shown in figure 1 [5].Friction due to rubbing between the spider and the yoke bores is minimized by incorporating needle-roller bearings between the hardened spider journals and hardened bearing caps pressed into the yoke bores.

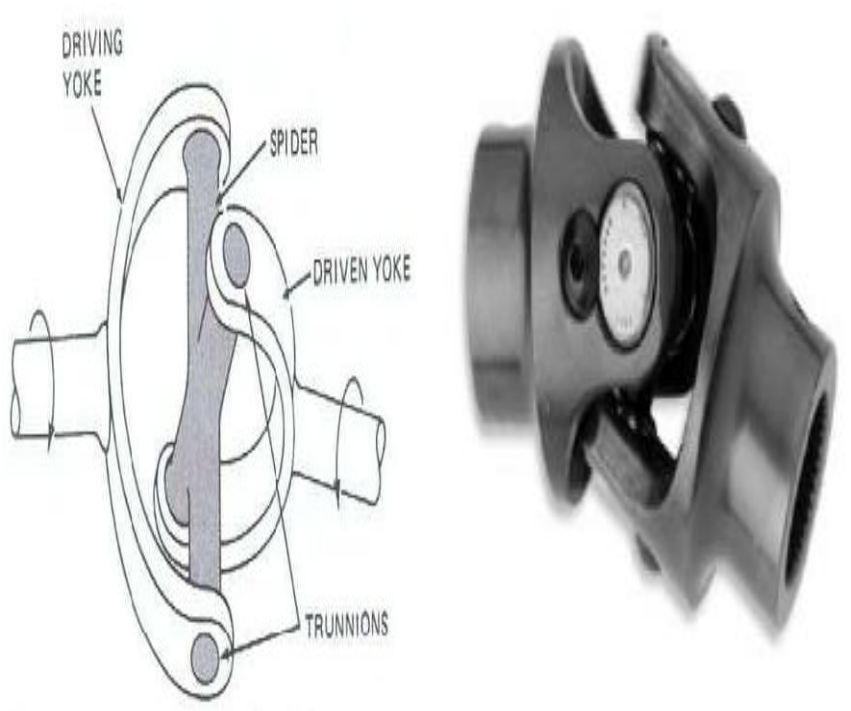

Fig 1: Steering Yoke assembly.

For modeling of the component, CATIA V5 R17 software is used. Preprocessing work like meshing and analysis work is carried out in HYPERWORKS software. Using FEA analysis, we can identify the nature and characteristics of stresses acting on the yoke and also evaluate the influence of the loads/ mass/ geometry/ boundary conditions over the yoke [4]. Figure shows the 3D model geometry of steering yoke assembly. 


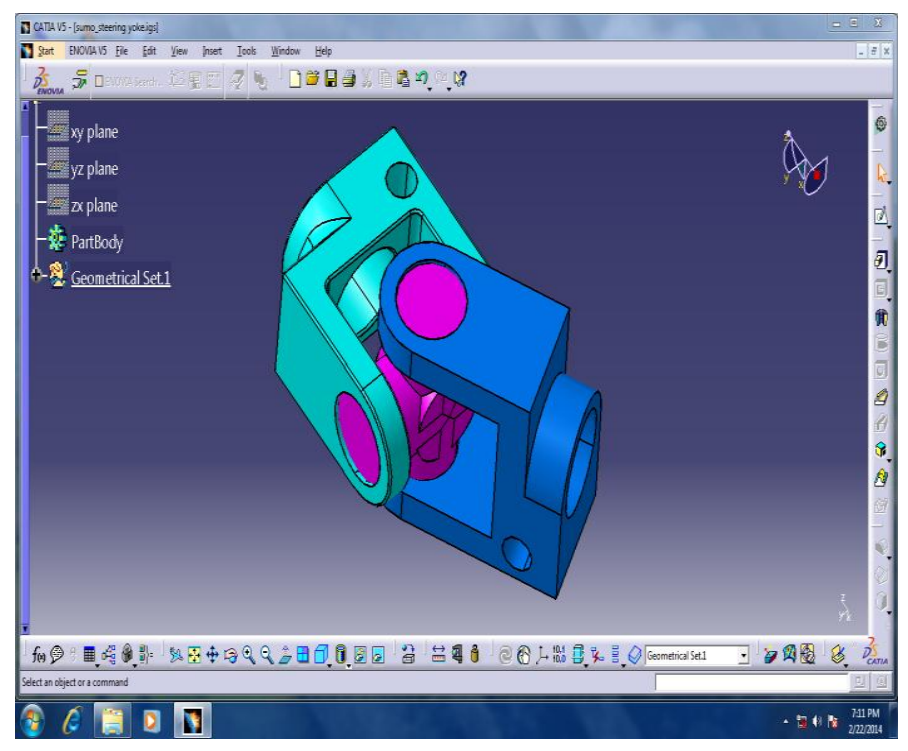

Fig 2: 3D Geometry Steering Yoke assembly

\section{PROBLEM STATEMENT}

Yoke assemblies are one of the most important components in steering system of an automobile. It generally subjected to torsional Stress and bending stress due to weights of components. Thus, these rotating components are susceptible to fatigue by the nature of their operation [6]. Drivers will lose control of their vehicle if the Steering shafts broke during the vehicle operation concerning. Because of this, human life can be in great danger if we don't know when, where and how the yoke will fail. It is very important to know the accurate prediction for the yoke to fail [7].

\section{OBJECTIVE}

The main aim of the project is to determine the Von Misses stresses, Element density distribution and Optimization in the existing Steering yoke. If the existing design shows the failure, then suggest the minimum design changes in the existing Steering yoke. A lot has been done and still a lot has to be done in this field. In this Project, only the static FEA of the Steering yoke has been performed by the use of the software. The study identified fatigue strength as the most significant design factor in the optimization process. Then the combination of finite element technique with the aspects of weight reduction is to be made to obtain the required design of Steering yoke [7-8].

\section{GENERIC SPECIFICATIONS FOR A} STEERING YOKE

- Material used: - Rolled/ Forged Steel - Carbon Steel C1021 or suitable

- Heat Treatment - Annealed.

- Typical hardness of the material - HRC 35-48

- Application for case study -Automobile (Steering yoke)
Table 1: Mechanical properties of C-1021 Steel

\begin{tabular}{|l|l|}
\hline Properties & Value \\
\hline Tensile strength, (MPa) & 420 \\
\hline Yield strength (MPa) & 230 \\
\hline Young's modulus, E (GPa) & 205 \\
\hline Elongation (\%) & $24 \%$ \\
\hline Reduction in area (\%) & $48 \%$ \\
\hline
\end{tabular}

\section{ANALYSIS OF STEERING YOKE BY USING HYPERWORKS}

With the advancement of finite element analysis (FEA) modeling, model-based design of mechanical structures is replacing the traditional trial-and-error approach. Here the finite element analysis of steering yoke is done in hyperworks software. For using any commercial software there are three steps. 1. Pre-processing, 2.processing (or) solution, 3.Postprocessing.

\subsection{Pre-processing}

After modeling the component and importing to hypermesh window meshing is carried out (Fig. 3) the tetrahedral meshing approach is employed for the meshing of the solid region geometry. Tetrahedral meshing produces high quality meshing for boundary representation of solid structural model. Since the tetrahedral is found to be the best meshing technique Divide the whole model into several parts and mesh one by one in different mesh densities. Although meshing by this way can produce more elements than by painstaking meshing, the advantages of saving time and easy operation is excellent. In addition, you can trim the surface artificially and a new surface edge will produce which will be the element edge after meshing.

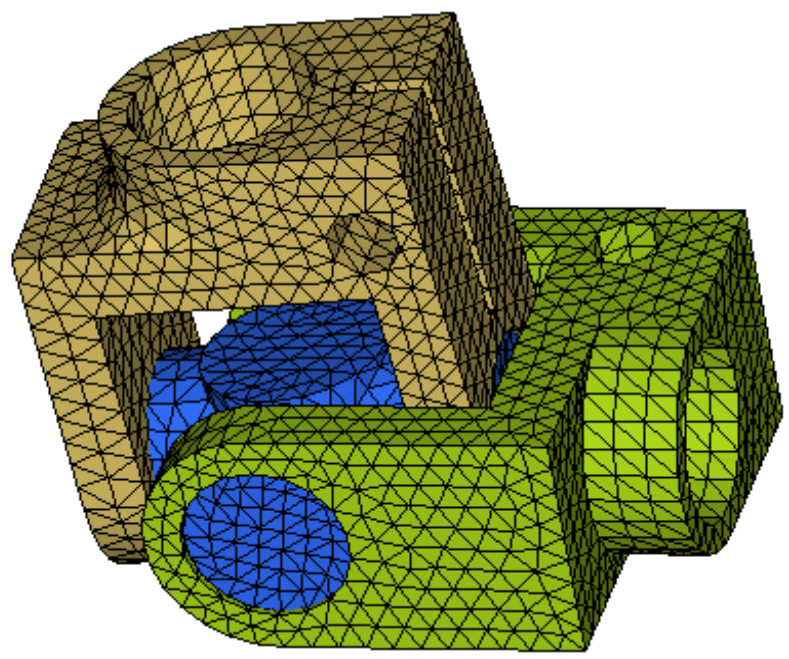

Fig 3: iges converted to $2 d-$ mesh 


\section{Meshing details-}

Number of elements $=27997$

Number of nodes $=28647$.

Element size $=2.5$

Mesh type $=$ Second order Tetrahedral meshing

\subsection{Processing}

After pre-processing, Loads \& boundary conditions are applied as shown in figure no.4.

Boundary conditions - $350 \mathrm{Nm}$ torque applied at top of steering yoke.

Constraint i.e. translation and rotational (1-6) at lower side

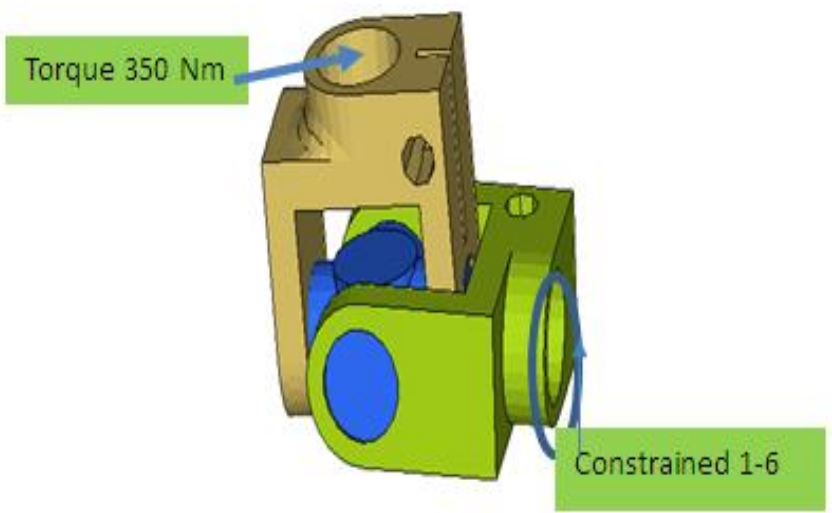

Fig 4: Boundary conditions

\subsection{Torque Applied}

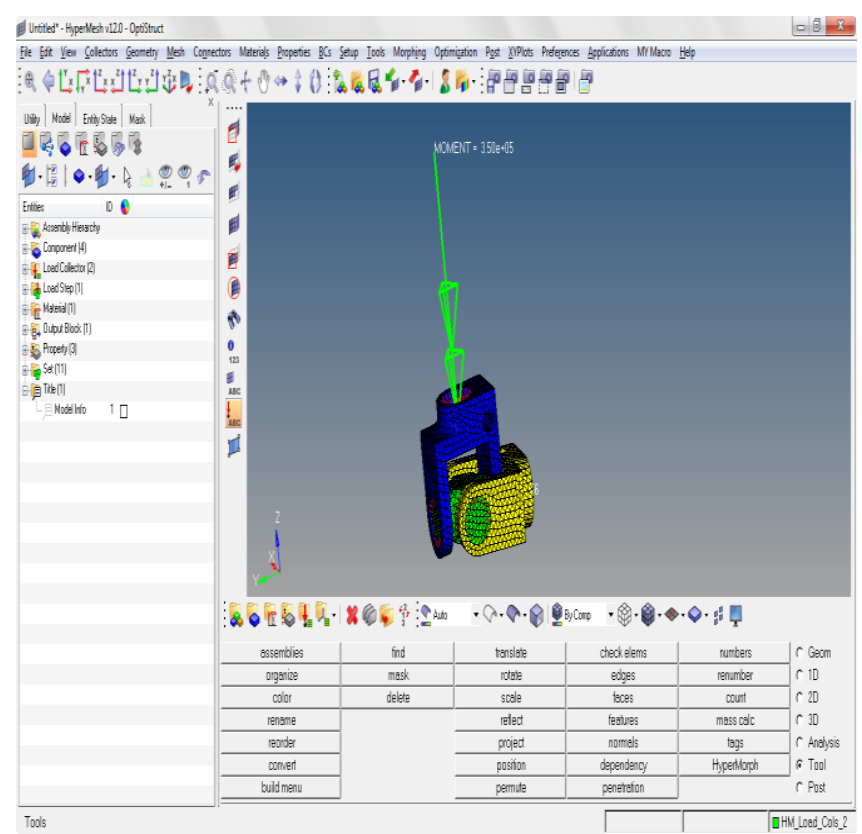

Fig 5: Torque applied
The arrow indicates the torque applied to the component.

\subsection{Post Processor}

\subsubsection{Hyperview}

After successfully completed the process, the results can be viewed in hyper view. To view the results 'hyper view' panel next to optistruct is selected. In the hyper view the results are displayed. The two important results are noted and they are: 1.Von mises elemental stress 2.Displacement. Firstly the component was designed for that vonmises elemental stress and displacement results are obtained from hyperworks

\subsubsection{Von Mises Element Stress for Existing Yoke}

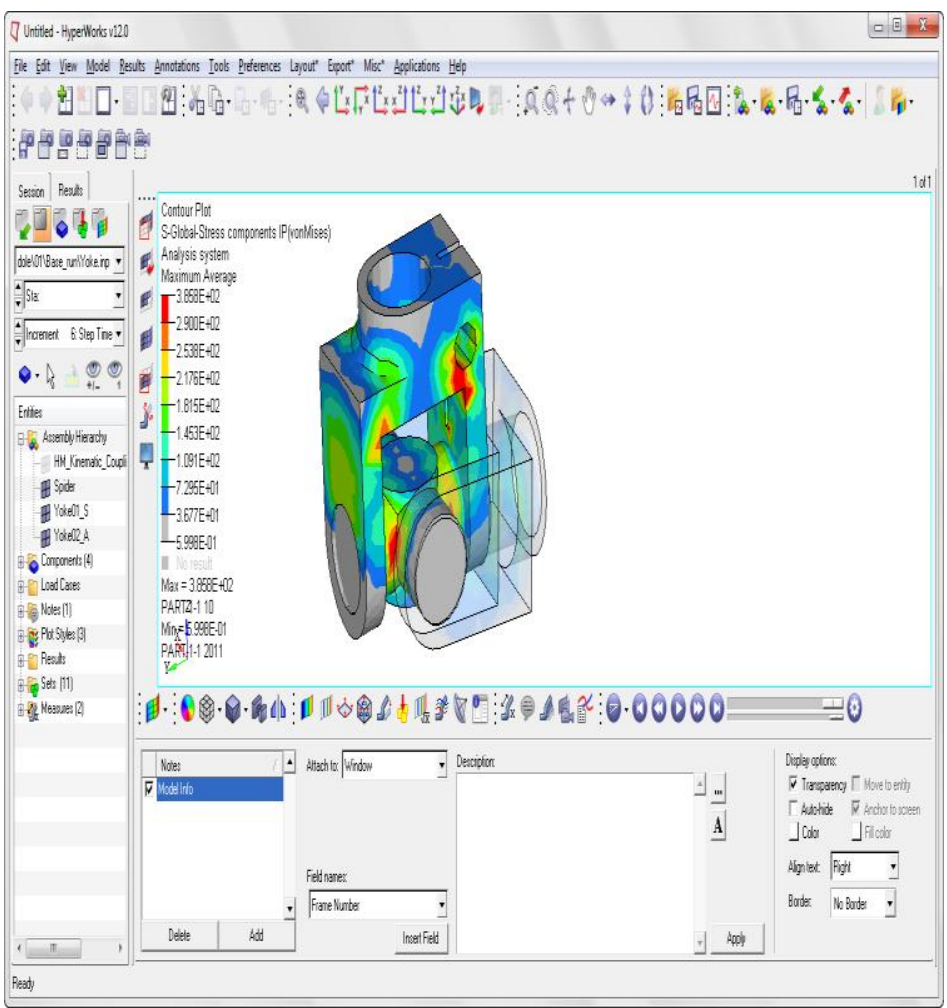

Fig 6: Von mises element stress for existing yoke

Von mises element stress $=3.858 \times 10^{7} \mathrm{~N} / \mathrm{m}^{2}$. All the units in S.I.units. Therefore, elemental stress $=386 \mathrm{MPa}$ (since $1 \mathrm{MPa}$ $=10^{6} \mathrm{~N} / \mathrm{m}^{2}$ ) 


\subsubsection{Displacement Counter for Existing Yoke}

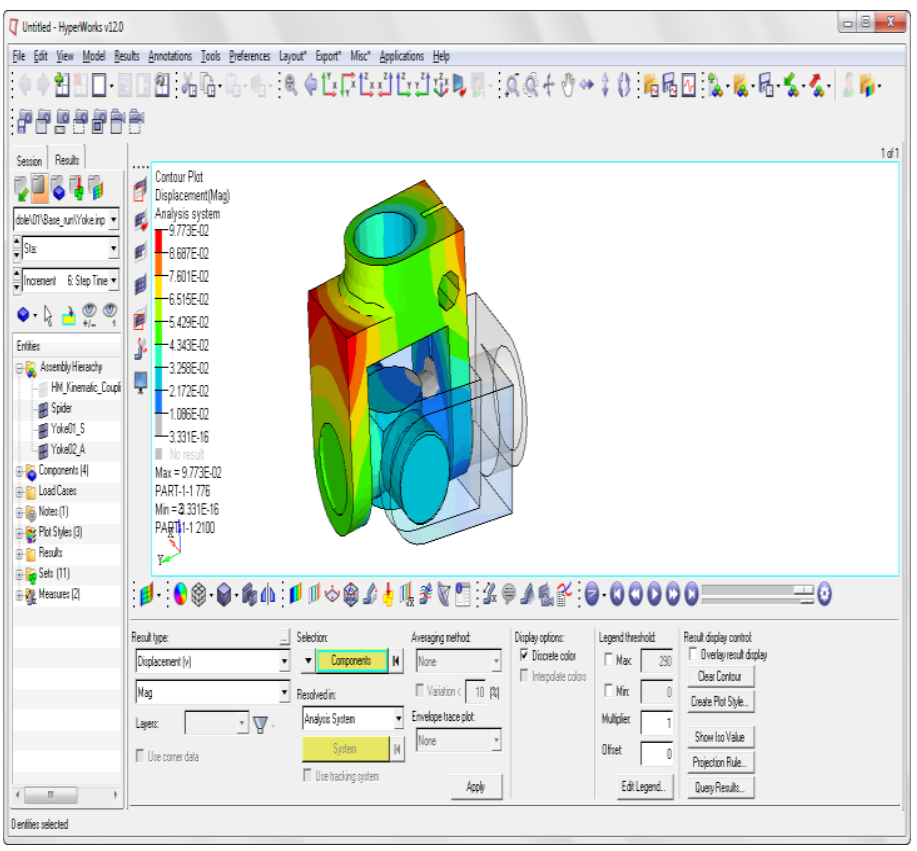

Fig 7: Displacement counter

Displacement $=9.773 \times 10^{-2} \mathrm{~mm}$.

\section{OPTIMIZATION APPROACH}

Maximum Stresses observed in existing steering Yoke is less than the yield stress of the material. Hence the design of steering yoke is unsafe.

The optimization of the steering yoke carried out using topology optimization technique. The optimization focused on the uncritical sections as show in figure 8 , which need to be reduced. From the topology optimization, it is suggest the unnecessary shape and design of the steering yoke. Optimizing the part design to meet the required stress values are carried out to avoid failure of the design [8].

\subsection{Element Density Distribution}

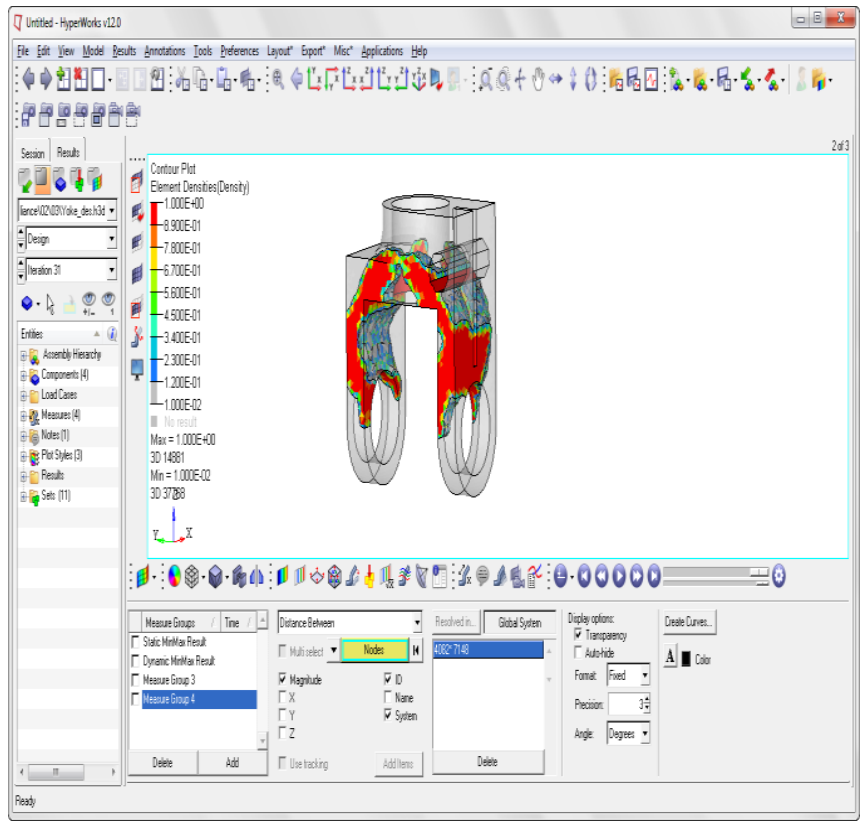

Fig 8 Element density distribution

Gray color region describes dead zone or elements from same region are not contribute to external load. There is a scope of removing material from same region

\subsection{Von Mises Element Stress for Modified Yoke}

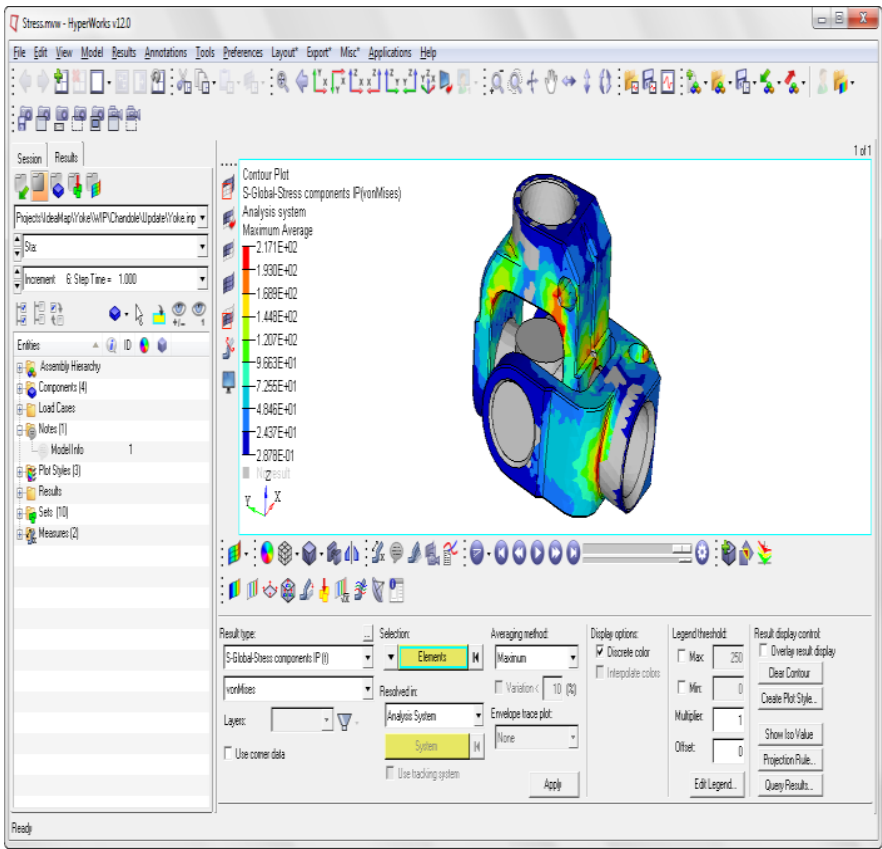

Fig 9: Von mises element stress for modified yoke

Von mises element stress $=2.171 \times 10^{7} \mathrm{~N} / \mathrm{m}^{2}=217 \mathrm{MPa}$. 


\subsection{Displacement Counters for Modified Yoke}

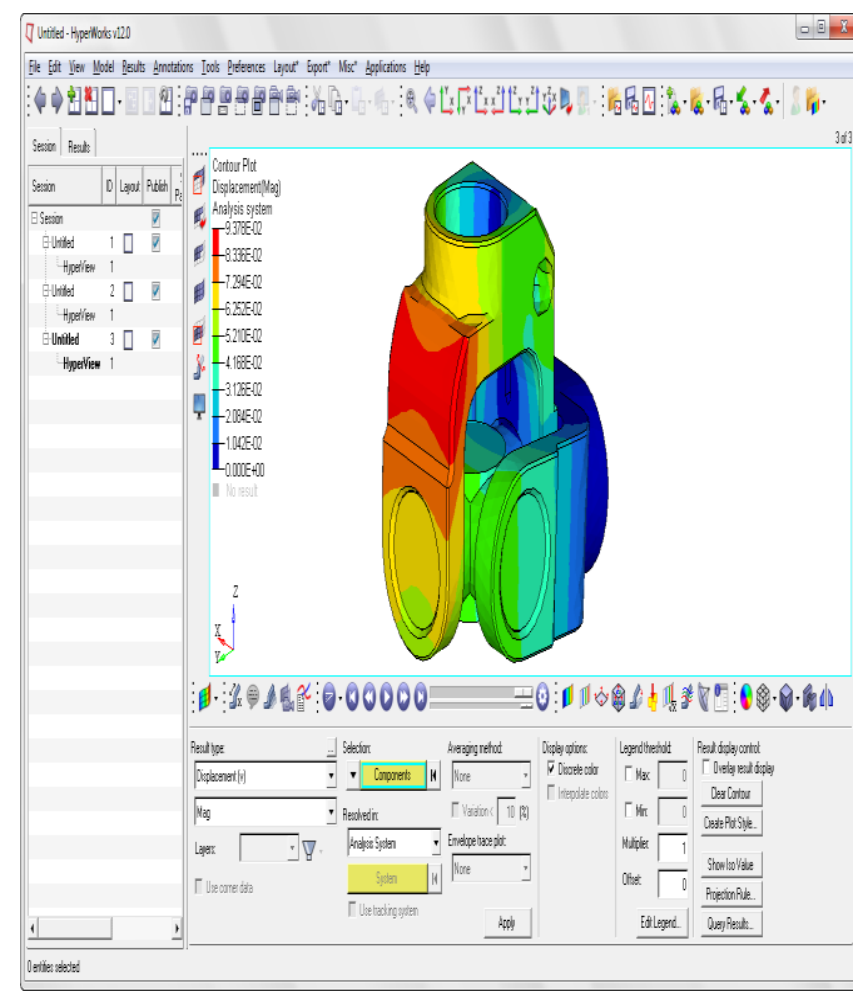

Fig 10 Displacements counter for modified yoke

Displacement $=9.378 \times 10^{-2} \mathrm{~mm}$.

\section{RESULTS}

Material used: Rolled/ Forged Steel.

Trade name: Carbon Steel C1021

Thus the steering yoke is meshed and analyzed by using hyperworks software and the results are obtained. Here the results obtained i.e. Stresses observed in modified yoke are greater than yield limit. There is no plastic straining and permanent set. Therefore the steering yoke is safe.

Table2: Comparison / Interpretation of the results

\begin{tabular}{|l|c|c|}
\hline \multicolumn{1}{|c|}{ Parameters } & $\begin{array}{c}\text { Existing } \\
\text { yoke }\end{array}$ & $\begin{array}{c}\text { Modified } \\
\text { yoke }\end{array}$ \\
\hline Torque $(\mathrm{N}-\mathrm{m})$ & 350 & 350 \\
\hline Maximum stress $(\mathrm{MPa})$ & 386 & 217 \\
\hline Displacement $(\mathrm{mm})$ & $9.773 \times 10^{-2}$ & $9.378 \times 10^{-2}$ \\
\hline
\end{tabular}

\section{CONCLUSIONS}

In this work 'design and finite element analysis of steering yoke in automobiles by hypermesh is carried out The element stress analysis of steering yoke covers the maximum stress and structure is expected to sustain, without fatigue failure. Hence steering yoke is analyzed for the stress produced under torque/load conditions. The result reveals that

- $\quad$ Steering yoke is analyzed under torque load $350 \mathrm{~N}-\mathrm{m}$ from steering column.

- Maximum stress observed in the modified steering yoke is $217 \mathrm{MPa}$ (Material Yield stress $250 \mathrm{MPa}$ )

- Maximum Stresses observed in Yoke is well below the yield stress value of the material. NO plasticity observed in the part. Hence the design is safe.

\section{ACKNOWLEDGEMENTS}

The author special thanks for valuable guidance by Mechanical Engineering department of S.N.D. College of Engineering \& Research, Yeola (Nasik). Also grateful acknowledge to Mechanical Engineering department of Late G.N.Sapkal College of Engineering, Anjneri, (Nasik).

\section{REFERENCES}

[1] S.Kinme, T.kamikawa and A.nishino "Development of stamped Yoke for high rigidity intermediate shaft" Technical report, Koya engineering journal English edition No. 165E (2004)

[2] Dr. Kirpal Singh, "Automobile Engineering" Volume 1, Standard publication publications, New Delhi, 2004, Page no.10-15.

[3] R. B. gupta, "Automobile engineering" 12th edition2009,Page No.538-539 \& 595-606.

[4] Mr. P.G. Thate and Prof. D.S. Bajaj, "Review on Failure Analysis of yoke assembly of a transmission drive shaft subjected to Torsion and Shear" IJERT, ISSN: 2278-0181 Volume-2, Issue-10, October-2013.

[5] Siraj Mohammad Ali Sheikh, "Analysis of universal coupling under different torque condition" IJESAT, ISSN: 2250-3676 Volume-2, Issue-3, 690-694 2012.

[6] H. Bayrakceken, S. Tasgetiren and I. Yavuz , "Two cases of failure in the power transmission system on vehicles: A universal joint yoke and a drive shaft" Science direct, Engineering failure analysis 14 (2007) 716-724.

[7] Scott Randall Hummel and Constantin Chassapis, "Configuration design and optimization of universal joints with manufacturing tolerances, Mechanism and Machine" Mechanism and machine theory 35 (2000) 463-476.

[8] M.S. Shaari, M.M. Rahman, M.M. Noor, K. Kadirgama and A.K. Amirruddin1 "Design of connecting rod of internal combustion engine: a topology optimization approach" National Conference in Mechanical Engineering Research and Postgraduate Studies (2nd NCMER 2010) 3-4 December 2010. 